LBNL No. 49283

\title{
Examples of Cooler Reflective Streets for Urban Heat-Island Mitigation: Portland Cement Concrete and Chip Seals
}

\author{
M. Pomerantz, H. Akbari, S.-C. Chang, R. Levinson and B. Pon \\ Heat Island Group \\ Energy Analysis Department \\ Environmental Energy Technologies Division \\ Lawrence Berkeley National Laboratory \\ Berkeley, CA 94720
}

\begin{abstract}
Part of the urban heat island effect can be attributed to dark pavements that are commonly used on streets and parking lots. In this paper we consider two light colored, hence cooler, alternative paving materials that are in actual use in cities today. These are Portland cement concrete (PCC) pavements and chip seals. We report measurements of the albedos of some PCC and chip sealed pavements in the San Francisco Bay Area. The albedos of the PCC pavements ranged from about 0.18 to 0.35 . The temperatures of some PCC pavements are also measured and calculated. We then consider how the albedos of the constituent materials of the PCC (stone, sand and cement) contribute to the albedos of the resulting finished concrete.

The albedos of a set of chip sealed pavements in San Jose, CA, were measured and correlated with the times of their placement. It is found that the albedos decrease with age (and use) but remain higher than that of standard asphalt concrete (AC) for about five years. After that, the albedos of the chip seals are about 0.12 , similar to aged AC. The fact that many PCC pavements have albedos at least twice as high as aged AC suggests that it is possible to have pavement albedos that remain high for many years.
\end{abstract}

\section{Introduction}

It is well documented that the daytime temperatures of large cities are higher than their suburbs. This "urban heat island" (UHI) effect is a problem in warm climates in the summers because it exacerbates the demand for electricity for air conditioning and increases the concentration of smog (Akbari et al. 1992). Some of the causes of the UHI are difficult to remedy (e.g., restricted airflow because of buildings, necessary human activities that release thermal energy), but some are within our easy control. Cities necessarily replace most of the bare ground and vegetation with impermeable surfaces such as buildings and pavements. The first effect of these changes is to reduce the cooling caused by evaporation of water. This again is difficult to reverse; nevertheless efforts are underway to add vegetation in cities. But the color of the impermeable surfaces may be open to choice and it affects the temperatures within the city. The effect of color is understandable because if a surface is dark it means it has absorbed the visible light. This warms the surface, which eventually warms the air. The most practical means of mitigating the UHI is to make urban surfaces whiter, by which we mean more reflective of the sunlight, both visible and invisible (mostly infrared). The quantitative measure of the total solar reflectivity is 
called "albedo"1. The common paving material for urban streets is asphalt concrete ${ }^{2}$ (AC), which is one of the darkest surfaces in the city. Fresh $\mathrm{AC}$ has an albedo of 0.05, which means about $95 \%$ of sunlight is absorbed by a fresh asphaltic surface. In this paper we will examine the reflective properties and temperatures of a sampling of two types of pavements other than AC found in cities today that have higher albedos. These are Portland cement concrete (PCC) and chip seals.

Paved surfaces contribute considerably to the temperature of cities because they cover a remarkably large fraction of urban surfaces. Detailed examination of Sacramento (Akbari et al. 1999) shows that $39 \%$ of the area seen from above the tree canopy was paved (including roads, parking areas, sidewalks). A quick estimate of the urban road area alone can be obtained from readily available data on the length of roads serviced by a given municipality. For example, the total length of public roads of San Francisco County, which is completely built-up, is $1437 \mathrm{~km}$ (893 miles). The total land area is 117 square $\mathrm{km}$ (45 square miles) (Cal-Stats 1990). Taking the average width of a street as $9.1 \mathrm{~m}$ (30 feet), we calculate that the total area of roads is about 13 square $\mathrm{km}$ ( 5 square mi). Thus the road area within this built-up city is about $11 \%$. There are considerable additional areas of paved driveways, sidewalks, and parking areas at homes and businesses. Our earlier work (Pomerantz et al. 2000) focussed on AC because it is the preponderant paving material for urban streets, by a ratio of about 9 to 1 .

Estimates of the benefits of cooler pavements have been made by mesoscale computer simulations (Taha et al. 1999), and also by general reasoning (Pomerantz et al. 2000) about the causes of heating in cities. Both approaches suggest that full deployment of pavements whose albedo is about 0.3 would decrease the peak air summer temperature of cities by as much as $0.5^{\circ} \mathrm{C}\left(1^{\circ} \mathrm{F}\right)$, in cases of hot cities whose temperature is not influenced much by winds from the surroundings. The magnitude is comparable to the decrease in temperature expected from the installation of cooler roofing. (The possible change in albedo of roofs is larger, but the area of pavements is larger.) Cooler roofing is more effective because, in addition to its indirect effect on ambient temperatures, it imparts a large and immediate energy benefit directly to the building on which it is installed (Akbari et al. 2001). But the choice between roofs and pavements is not "either/or." These are two different problems and one can aim for progress on both fronts, without conflict between them. The potential benefits in smog prevention and energy saving make it worthwhile to try to find means to achieve cooler pavements. The reduction of warming in the winter is an acceptable penalty in hot places because the sun heats less strongly and for shorter times in the winter. Moreover, the energy efficiency for heating by burning fuel may be greater than converting fuel to electricity and then powering air conditioners, depending on the efficiencies of the air-conditioners and the amount of heating vs. cooling. In this paper we focus on the physical properties of two possibilities: PCC and chip seals.

An important issue is the cost of the lighter colored chips or cement concrete. This aspect has been extensively considered elsewhere (Ting et al. 2001) and so is not addressed here. The

\footnotetext{
${ }^{1}$ The albedo of a surface is defined as the ratio of the reflected to incident solar light. This is averaged over the solar spectrum and all angles in a hemisphere. A perfect reflector has $\hat{a}=1$; no reflection is denoted by $\hat{a}=0$.

2 "Concrete" is a generic term for stony aggregate held together by a binder. If the binder is asphalt, the composite is properly called "asphalt concrete" (AC). In common usage it is referred to as "asphalt". Similarly, if the binder is Portland cement, the material is properly called "Portland cement concrete," or PCC, although in common usage it is termed "concrete". We adhere to the precise terminology.
} 
general consideration is that, usually, the materials used are those readily available locally. For example, in San Jose, CA, both dark and light colored aggregate are available at the same cost. It is mostly by chance that the Public Works Department chooses the lighter colored aggregate. The problem of the availability of light-colored aggregate is local, but if it is available at a reasonable price it provides the benefits outlined in this paper.

Some of the physical properties of PCC that might yield benefits in the UHI have been considered by others. The differences between the heat flows below surfaces of soil and concrete were observed (Doll et al. 1985). The effect on the temperature of the lower atmosphere of infrared re-radiation from the surfaces was modeled (Asaeda et al. 1996). These works did not address the practical questions of what the albedos of actual cooler pavements are, and why they are what they are.

Chip seals are a standard method (Asphalt-Institute 1989) of preventive maintenance and rehabilitation of worn pavements. Despite the use of asphalt as the binder, the surface that is achieved may be light colored because the process is to spread aggregate chips on the top. When pressed into the asphalt, a dense covering of aggregate is achieved; the aggregate determines the color of the pavement when it is new.

Currently PCC is typically used for sidewalks, patios, bridge decks, elevated highways and parking lots and heavily traveled roadways, especially those frequented by trucks. There are also cities that have chosen to use PCC for streets and local highways.

Chip seals — sometimes called "surface treatments" (Asphalt-Institute 1989) —are used as preventive maintenance and for rehabilitation. For example, the Michigan Department of Transportation reported (FHWA 1997) that preventive maintenance is more than six times as cost-effective as rehabilitation and reconstruction. (Not quite the ratio of an ounce of prevention worth a pound of cure-but close). Chip seals are among the methods used in Michigan. Even after deterioration has advanced, surface rehabilitation with chip seals may be used to extend the life of a pavement, before in-depth reconstruction is performed. A similar process is used in Switzerland to maintain the pavements and improve the skid resistance. Called "roll-split," aggregate is spread on asphalt pavements in the hot months and is rolled into the surface by the traffic.

In the present paper, we discuss PCC and chip seals because they are familiar to engineers and public works officials and thus do not have the additional barriers faced by totally new and untested technologies. We review the materials and processes of laying PCC pavements, with comparison to AC. Our main concern is with the albedos, â, of the pavements, so we report measurements of â of a sampling of PCC pavements in our geographical area. Temperatures of the pavements were also measured during the course of a day, and this is compared to calculations of heat flow. We report a study of the albedos of some concretes compared to the albedos of the components from which they were made. With appropriate components (cement, sand, stone) PCC can be made quite reflective of sunlight.

We also report measurements of albedos of chip-seals on the streets of San Jose. That city has used chip seals for more than twenty years for regular maintenance. Thus we were able to measure the changes in albedo of comparable pavements placed in different years. This gives an idea of the persistence of the higher albedo under the influences of weather and use. We also show data on the variation of pavement temperature with the albedos of the chip seals. 
We draw conclusions about the practicality of increasing the pavement albedo using these wellknown techniques. We conclude that, despite the effects of soiling and aging, the average albedos of urban pavement can be increased, with resulting beneficial reductions in energy consumption and smog generation.

\section{The materials and processes of PCC}

The purpose of a pavement is to provide a solid surface for vehicles and pedestrians. Ideally this would be a solid rock pathway. But to adjust to the contour of the path, rocks are broken into small pieces (aggregate) and then reassembled into the desired form. A binder is added to prevent the aggregate from dispersing under the forces of traffic and weather. The common types of binder are asphalt and Portland cement. Asphalt is derived from petroleum and is a thermoplastic material. As the temperature is lowered it hardens and acts as a glue to bind the aggregates into an asphalt concrete (AC). Portland cement is derived from calcium and silicon oxides (see Appendix A for details). When mixed with water, a chemical reaction occurs which causes the grains of cement to attach to each other and to the aggregates (Leighou 1942) to form a Portland cement concrete (PCC).

The procedure for making a PCC pavement is to thoroughly mix the components in approximate proportions (wgt \%): cement/ sand/ stone/ water $=14 / 35 / 45 / 6$. To make 0.766 cubic meters (one cubic yard) of PCC one may choose to use $255 \mathrm{~kg}(564 \mathrm{lb}$.) of cement, about $636 \mathrm{~kg}$ (1400 lb) of sand, about $772 \mathrm{~kg}(1700 \mathrm{lb})$ of aggregate and about 148 liters $(37 \mathrm{gal})$ of water [about $148 \mathrm{~kg}$ (300 lb.)]. Actual proportions vary depending on the materials available, desired strength and other properties (Mantell 1958). This amount of PCC weighs about $900 \mathrm{~kg}$ (two tons). (Cement trucks contain in the range of 6 to 11 cubic meters ( 8 to 14 cubic yards).) The concrete may contain 2 to $8 \%$ by volume of air voids to protect against damage by freeze-thaw in the winter.

The viscous mixture is poured into forms of the desired size and then "finished" or smoothed. It is allowed to "cure" or set. The curing period lasts from five to seven days after placement for conventional concrete but faster-curing PCCs have also been developed. Curing is one of the most important steps in concrete construction, because proper curing greatly increases concrete strength and durability. Concrete hardens as a result of the chemical reaction between cement and water. However, this occurs only if water is available and if the concrete's temperature stays within a suitable range. During the curing, the concrete surface needs to be kept moist to facilitate the hydration process. New concrete can be kept wet with hoses, sprinklers or wet burlap covers. A coat of commercially available curing compounds, which seal in moisture, can also be applied. Heat is generated during curing and may cause expansion and subsequent shrinkage. Shrinkage due to the evaporation of free water may also occur. PCC is called a "rigid" pavement and it can crack. Cracks are controlled by tooling or by otherwise creating joints in slabs. This creates a plane of weakness that causes cracks to occur at preferred places rather than randomly.

\subsection{Laboratory measurements of albedos of PCC samples and components}

Since PCC is composed of three materials each with its own â, it is of some interest to examine the influence of each component on the â of the final concrete. We give some examples in Table $\mathbf{1}$. The materials are typical of commercial PCC and were kindly provided by contractors. The â were measured in our laboratory using a Devices and Services Solar Spectrum Reflectometer. The constituent cements, sands, and rocks were placed on plates that were brought as close as possible to the $2.5 \mathrm{~cm}(1 ")$ aperture of the instrument. In some cases, the albedos of the 
aggregates were made on single stones seen through a small aperture, and scaled to the albedos of standard samples (see Levinson et al. for details of this method [Levinson et al. 2002]). The measurements of the concrete samples were of the upper surfaces of cylindrical cores. The samples were at least months old and were thus thoroughly dry and cured before they were measured. These surfaces have roughness typical of commercial PCC.

Table 1 gives the albedos of the cements, sands and aggregates used in each concrete, and the â of the finished concrete. In the case of the Calaveras/So Cal sample, two aggregates with different sizes but about the same â were used. For each sample, the weight \% of each component when known is included in Table 1. The notable overall result of these measurements is that the albedo of the concrete is higher or equal to the albedos of any of its constituents. That the albedo might be the same as the cement or sand can be understood as a consequence of the finishing process that leaves the upper surface relatively rich in cement. A construction manual says that proper practice is achieved when "...the submerged coarse aggregate is barely visible on the concrete surface..." (FHWA 1984)(p. VI-78). Then the cement and sand mortar ("cream") will dominate the color. The cement will also tend to control the color because it coats the other ingredients in order to bond the mixture together. Thus, as in the case of asphalt concrete, a relatively small amount of binder coats everything else and becomes the controlling factor.

It is perhaps puzzling when the concrete albedo measures higher than any of its constituents. One factor may be that the measurements on the constituents were made on irregular surfaces (sands and rocks) but the concrete is smoother. To check this we measured one kind of material, Watsonville granite, of three different diameters, $\mathrm{D}$, and found the corresponding â $\mathrm{s}$. The results were: for $\mathrm{D}=0.6 \mathrm{~cm}(0.25$ in. $), \hat{a}=0.25$; for $\mathrm{D}=1.2 \mathrm{~cm}$. $(0.5 \mathrm{in}$.), $\hat{a}=0.34$; for $\mathrm{D}=2.5 \mathrm{~cm}$. (1.0 in.), $\hat{a}=0.34$. This may indicate that the measured albedos depend on the roughnesses of the samples. This can be understood on the basis that if the sample contains many irregular facets the

\begin{tabular}{|c|c|c|c|c|}
\hline Source $\longrightarrow$ & $\begin{array}{c}\text { Calaveras/ So. } \\
\text { Cal }\end{array}$ & $\begin{array}{l}\text { Calaveras/ } \\
\text { Fresno }\end{array}$ & $\begin{array}{l}\text { Calaveras/ } \\
\text { Seattle }\end{array}$ & Southdown \\
\hline$\hat{a}$-Cement- & 0.29 & 0.30 & 0.33 & 0.30 \\
\hline Wgt. \% & 14 & 13 & & 14 \\
\hline$\hat{a}$-Sand- & 0.31 & 0.21 & 0.10 & 0.16 \\
\hline Wgt. \% & 36 & 31 & & 34 \\
\hline$\hat{a}$-aggregate $1-$ & 0.30 & 0.20 & 0.27 & 0.40 \\
\hline $\begin{array}{l}\text { Wgt.\% } \\
\text { (Diameter /cm) }\end{array}$ & $30(\mathrm{D}=2.5)$ & $48(\mathrm{D}=2.5)$ & $(\mathrm{D}=1.9)$ & $45(\mathrm{D}=2.5)$ \\
\hline$\hat{a}$-aggregate 2 & 0.29 & & & \\
\hline $\begin{array}{l}\text { Wgt.\% } \\
\text { (Diameter/cm) }\end{array}$ & $12(\mathrm{D}=0.7)$ & & & \\
\hline$\hat{a}-$ Concrete & 0.42 & 0.33 & 0.35 & 0.45 \\
\hline
\end{tabular}

Table 1. Albedos of components and of the finished PCC s made of them. The weight of the water, not shown, makes up the remaining weight $\%$. 
light may be multiply reflected. Each reflection off the faces leads to some absorption, and the overall reflectivity is lower simply due to the physical form. There may also have been leakage of light because the sample shape prevents it from being fitted to the aperture. A second explanation may be that the compounds created during the chemical reactions of the cement with water have a different $\hat{a}$ from the original reactants. Thus, even with knowledge of the constituent â, the prediction of the â of concrete might be a difficult problem involving the chemistry of the components.

Although this paper focuses on traditional grey colored PCC, it is possible to obtain quite high reflectivities of PCC by using white cement and aggregates. Whiteness of cement is increased by eliminating strongly-colored compounds, such as iron oxide ${ }^{3}$. We have measured a sample of Lehigh white concrete to have $\hat{a}=0.75$. The TXI Riverside website says "We strive to maintain a reflectance of $88 \%$ for our White Cement."

An extensive study of PCC made with a variety of aggregates and cements (Levinson et al. 2002) indicates that the albedo of properly cast PCC correlates with the albedos of the cement, the sand, and, if abraded to expose it, the stone as well. Higher albedo of PCC is most strongly correlated with the albedo of the cement.

\subsection{Field measurements of albedos and temperatures of PCC pavements}

It is of interest to know the albedos and temperatures of actual PCC pavements. We thus located examples of PCC pavements and measured them. The details of the methods used to make the measurements are presented in an earlier work (Pomerantz et al. 2000). Surface temperatures were measured with a Raytek Infrared Thermometer. Albedos were measured according to ASTM Standard E1918-97, "Standard Test Method for Measuring Solar Reflectance of Horizontal and Low-Sloped Surfaces in the Field." The method requires suspending a pyranometer about $0.5 \mathrm{~m}$ above the surface. The ratio of the (reflected) radiation measured when the pyranometer is pointing downward to the (incident) radiation when pointed skyward is the albedo. We used an Eppley Precision Solar Pyranometer. This procedure was not practical on freeways during the middle of the day, for safety reasons. Thus our set of active pavements is comprised of smaller streets. This reduced the number of choices, but is closer to the application we have in mind: to cool as much of city streets, not merely highways, as possible. This necessarily means mostly residential streets, not freeways.

The total number of streets we measured is 16 . They are in the region of the "East Bay" of the San Francisco Bay Area. The histogram of the number of pavements vs. their albedos is given in Fig. 1. It shows a range of â from about 0.18 to 0.35 , with an average of 0.26 . This is lower than the average value of new and hardened PCC, $\hat{a}=0.36$, that we described in $\S 2.1$ above. This may be because of different starting materials; unfortunately we do not know what the albedos of the pavements were when they were new. Various additives are sometimes used to modify properties, and these can change the color. For example, so-called "pozzolans" (such as fly-ash) are sometimes added to improve durability. These make the color darker. The albedos surely change with use and soiling; this would reduce their albedos compared to new and hardened

\footnotetext{
${ }^{3}$ Although there are only two companies in the United States that manufacture white cements (Lehigh Portland Cement Corp., (http://www.lehighportlandcement.com/main.html) and TXI Riverside Cement http://www.cement.com/white.asp) they are widely available.
} 
PCC. This is uncontrolled in this sampling of pavements. It is notable that, in our set of samples, the albedos of actual pavements range as high as 0.35 and do not fall below 0.18 . We will return to this observation later.

We reported earlier (Pomerantz et al. 2000) that the temperature of a PCC with an â $=0.35$ was $13^{\circ} \mathrm{C}\left(23^{\circ} \mathrm{F}\right)$ lower than an $\mathrm{AC}$ pavement with $\hat{\mathrm{a}}=0.10$, in the afternoon of a sunny day in August in San Ramon, CA. We show in Fig. 2 the temperatures of a PCC pavement and an adjacent $\mathrm{AC}$ pavement during one whole day. The data were taken on a somewhat cloudy day, but nevertheless the surface temperature of the PCC pavement of $\hat{a}=0.25$ is $11^{\circ} \mathrm{C}\left(20^{\circ} \mathrm{F}\right)$ cooler than an $\mathrm{AC}$ pavement with $\hat{\mathrm{a}}=0.09$ at their peaks near 1 PM. In Fig. 3 we display the surface temperatures of two PCC pavements of different albedos $(0.20$ and 0.25$)$. The data are not very regular, but they indicate a dependence of the peak temperatures vs. albedo of about $7^{\circ} \mathrm{C}\left(12^{\circ} \mathrm{F}\right)$ for a 0.1 change in albedo of PCC. On this sunny day, the higher albedo surface reached $52{ }^{\circ} \mathrm{C}$ $\left(126^{\circ} \mathrm{F}\right)$ just after $1 \mathrm{PM}$. An $\mathrm{AC}$ pavement would be at least $10^{\circ} \mathrm{C}\left(18^{\circ} \mathrm{F}\right)$ hotter, as we now show.

\subsection{Calculations of the surface temperature of PCC pavements}

We now present calculations comparing the surface temperatures of cement and asphalt concrete pavements. From a survey of the literature, we obtain values of the necessary bulk physical parameters, the specific heat, $\mathrm{C}_{\mathrm{p}}$, the thermal conductivity, $\kappa$, and the density, $\rho$, of AC and PCC, as shown in Table 2. The thermal diffusivity, $\alpha$, may be derived ${ }^{4}$ from these properties according to $\alpha=\kappa / \rho C_{\mathrm{p}}$. Table 2 shows that the thermal properties of PCC and AC are not very different from each other. Note that the factor that determines the heat flow through the pavement, the thermal diffusivity, is about $\alpha \approx 5 \times 10^{-7} \mathrm{~m}^{2} / \mathrm{s}$ in both materials; it is $20 \%$ higher in the PCC than in the AC. We expect the convective and radiative properties to be about the same, because the roughnesses and the emissivities are about the same. Thus we expect the temperature of the pavement surface to be determined mostly by the energy absorbed at the surface-which is controlled by the albedo.

\begin{tabular}{|l|c|c|} 
& $\begin{array}{c}\text { Asphalt concrete } \\
\text { Specific heat }\left(\mathrm{C}_{\mathrm{p}}\right)[\mathrm{J} / \mathrm{gK}]\end{array}$ & $\begin{array}{c}\text { Portland cement } \\
\text { concrete }\end{array}$ \\
Thermal conductivity $(\kappa)[\mathrm{W} / \mathrm{m} \cdot \mathrm{K}]$ & 0.8 & 0.8 \\
Density $(\rho)\left[\mathrm{kg} / \mathrm{m}^{3}\right]$ & 2100 & 1.0 \\
Thermal diffusivity $(\alpha)\left[\mathrm{m}^{2} / \mathrm{s}\right]$ & $4.8 \times 10^{-7}$ & 2200 \\
\hline
\end{tabular}

Table 2. Thermal properties of asphalt- and Portland cement-concretes.

\footnotetext{
${ }^{4}$ On a more basic level, heat is sound waves that diffuse from the hot side to the cooler side. $\alpha$ is related to the velocity of sound, $v$, and the mean free path of thermal sound waves, $\ell$, by $\alpha=v \ell / 3$ (Kittel 1976). Using $\alpha \approx 5 \times 10^{-7} \mathrm{~m}^{2} / \mathrm{s}$ and a typical sound velocity in a hard solid $\approx 3,000 \mathrm{~m} / \mathrm{s}$, we obtain $\ell \approx 5 \times 10^{-10}$ $\mathrm{m}$. This says that a thermal wave travels a distance of only about 2 or 3 atoms before it is scattered. Typical pure single crystals (quartz and $\mathrm{NaCl}$ ) have $\ell \approx 30 \times 10^{-10} \mathrm{~m}$ at room temperature. In concretes, the presence of air voids, boundaries between the grains and the impurities in the components are the likely causes of the apparently short mean free paths of the thermal waves. The difference in the thermal diffusivities between the AC and PCC is probably due to the higher sound velocity in cement compared to asphalt. Concretes are about as poor heat conductors as a hard solid can be.
} 
Fig. 4 shows the results of our computer simulation ${ }^{5}$ of the temperature of an AC pavement as a function of time of day, for a particular insolation (taken on Sept. 17, 1997 in San Jose, CA) for albedos varying from 0.05 to 0.40 . In Fig. 5 are corresponding results for PCC. For the same albedo, say 0.05, the peak temperature of the $\mathrm{PCC}$ is lower than that of the $\mathrm{AC}$ by $2{ }^{\circ} \mathrm{C}$, when the wind is slow. This is the effect of the larger thermal diffusivity of PCC. The effect of albedo is found when we compare the temperatures of a PCC with albedo of 0.25 with that of a PCC pavement with $\hat{a}=0.05$. We observe that the higher albedo pavement is $10^{\circ} \mathrm{C}\left(18^{\circ} \mathrm{F}\right)$ cooler. It is $12^{\circ} \mathrm{C}$ cooler than fresh $\mathrm{AC}$, which reaches $69^{\circ} \mathrm{C}\left(156^{\circ} \mathrm{F}\right)$. The calculations give a dependence of the peak surface temperature on albedo of about $-4.5^{\circ} \mathrm{C}\left(-8.1^{\circ} \mathrm{F}\right)$ for an increase of 0.1 in albedo for both the PCC and the AC pavements. This is in reasonable agreement with the earlier reported measurements (Pomerantz et al. 2000) and those in the present paper. The quantitative agreement will depend on the amount of sunlight during the experiments compared to that assumed in the computations. But the computer calculation and experiments both suggest a change in peak surface temperature of about $-5^{\circ} \mathrm{C}\left(-9^{\circ} \mathrm{F}\right)$ for a 0.1 change in albedo in the summer (at the latitude of San Francisco, about $40^{\circ} \mathrm{N}$ ).

We note that there are analytic solutions of similar heat flow problems. The simplest case is when the surface temperature varies with sinusoidal time dependence with period $\Theta$. Sinusoidal temperature is an approximation to the daily cycle caused by sunlight; $\Theta=24$ hours. The solution (Jakob et al. 1957) is a temperature variation whose amplitude decreases with the distance from the surface, $x$, as $e^{-x / \delta}$, where $\delta=(\alpha \Theta / \pi)^{1 / 2}$. $\delta$ is a measure of the depth to which the temperature variation is transmitted into the pavement. Using a value of $\alpha=5 \times 10^{-7} \mathrm{~m}^{2} / \mathrm{s}$ we find $\delta=0.12 \mathrm{~m}$ as the depth where the temperature variation amplitude is reduced by $1 / e$. At a depth a few times $\delta$ the temperature is virtually unaffected by the diurnal surface variations. The time dependence of the temperature variation at the depth $x$ is also sinusoidal, but it is delayed behind the surface variation by a time $\Delta t=(x / \delta) \Theta / 2 \pi$.

A somewhat more realistic problem with an analytical solution is the case of a slab of thickness $L$ with one surface undergoing sinusoidal temperature variation and the other side at constant temperature (Morse et al. 1953) (vol. II, p. 1585 ets.). This approximates the diurnal heating at one surface and contact with the deep Earth at a constant temperature on the other side. Qualitatively, the solutions depend on the cycle time, $T$, compared to the diffusion ${ }^{6}$ time, $L^{2} / \alpha$. In the slow limit $T>>L^{2} / \alpha$; the heat flow can follow the surface temperature and the body achieves a smooth steady-state heat flow, multiplied by a slowly varying surface driving term. When $T<<L^{2} / \alpha$, the flow cannot follow the surface driving, and the temperature profile is wavy and decreased in amplitude. For our choice of pavement $\left(L=0.5 \mathrm{~m}\right.$ and $\left.\alpha=5 \times 10^{-7} \mathrm{~m}^{2} / \mathrm{s}\right)$, the value of $L^{2} / \alpha$ is about 140 hours. A 24 hour cycle is faster than the heat can be easily transported, and a wavy profile can be expected. This was observed in experiments (Asaeda et al. 1996) in which the value of $L^{2} / \alpha$ was about 50 hours (because the thickness of the pavement was $L=0.3 \mathrm{~m})$. An even more realistic problem, a surface heated by radiation, is sketched by

5 The method used for the calculation and the data for the insolation, are given in an earlier work (Pomerantz et al. 2000). The pavement thickness was taken as $\mathrm{L}=0.5 \mathrm{~m}$. The deep earth temperature was the daily average of the air temperature. The time step is 0.5 hours.

${ }^{6}$ The "diffusion time" is defined here as the time it takes for the temperature at a distance $L$ from a surface to reach about $50 \%$ of its change in temperature, when the surface temperature is changed to a new constant value (Jakob et al. 1957). 
Morse and Feshbach (Morse et al. 1953) (p. 1587). The qualitative features are the same as we just described.

\section{Materials and processes of chip seals}

It is a preferred practice in pavement management to prolong the lives of aged or damaged AC pavements by resurfacing with thin coatings. Among the techniques used for resurfacing, chip seals offer the possibility of lighter-colored, and thus cooler, surfaces. This is because the aggregate, and not black asphalt, is exposed at the surface of a chip seal. The standard procedure for fabricating a chip-seal is described in the Asphalt Handbook (Asphalt-Institute 1989) where it is called "surface treatment." This is also the terminology used by Means' catalogs of construction costs (Means 1996). We prefer to use the term "chip seal" as it better suggests the surface treatment in which aggregate ("chip") is placed sequentially after the asphalt binder. (Surface treatments in which the aggregates are mixed with asphalt before spreading include slurry seals; these are black when they are placed.) Specifications are given by the Asphalt Emulsion Manufactures Association (AEMA 1995) and updates are at their website, http://aema.org/.

The placing of a chip seal on an existing pavement involves, firstly, cleaning the surface and patching any large cracks. Then, in timely sequence, asphalt emulsion is spread on the surface, followed by uniformly graded aggregate sufficient to form one layer. Seating of the aggregate is achieved by riding over it with a vehicle with rollers. Subsequent traffic also presses the aggregate into the asphalt and packs it. The final stage is to sweep the street clear of loose aggregate, after allowing the asphalt to set. Clearly, this process is more complicated and thus more expensive than using a pre-mixed material such as a slurry seal. If not done properly (Janisch 1992) or if severe weather conditions result in freeze-thaw and snow plowing, chips can dislodge and be thrown by car tires. This is also a reason for avoiding chip seals in places where tires are turned hard, such as cul de sacs and tight parking places, or where cars move fast, such as arterial roads. Parking lots should use angled parking on chip seals. Nevertheless, even in northerly climates (Janisch 1992), chip seals have been successful while providing advantages of a surface with good skid resistance and higher albedo.

\subsection{Albedos of chip seals and how they got there}

We now present data on the albedos of actual chip seals currently found on streets. First, we compare the albedos of a new chip seal pavement with the albedo of the fresh aggregate from which it is formed. This tells us what the albedo of the aggregate must be in order to achieve the desired albedo of a pavement. We then compare the albedos of new and older roads in order to account for the changes that may occur with time.

A city that uses chip seals for normal maintenance is San Jose. With the cooperation of the Department of Public Works of San Jose, we identified a set of pavements that had been chip sealed over a maintenance cycle. Some were done during the year in which we made our first measurements (2000) and others as long ago as 1990. We were informed that the source of the aggregate used over these years was unchanged. We assume that the aggregate has been about the same for this time, and thus we compare the albedos of the old surfaces with the newer, and ascribe the differences to the histories of the pavements, not differences in the original aggregates. 
To compare the albedo of the pavement with that of the aggregate, we obtained from the San Jose Dept. of Public Works a sample of the aggregate used in their pavements. We measured its albedo with a D \& S Solar Spectrum Reflectometer as described in $\S 2.1$ above. The albedo of the aggregate was 0.20 . We also measured an albedo of about 0.20 of a pavement covered with a freshly laid chip seal made with this aggregate (see Fig. 6). Thus the initial albedo of a chip seal is the same as that of the aggregate from which it is made. In an earlier report (Pomerantz et al. 2000), we gave the results of measurements of small area chip seals we made ourselves. In these hand-made samples, the black asphalt emulsion showed between the aggregate particles. The result was a chip-seal albedo only about two-thirds as large as that of the aggregate. The chip seals made by the skilled pavers in San Jose are densely packed; no asphalt shows between the rocks. Then the albedo of the freshly finished pavement is the same as that of the aggregates themselves.

When subjected to use and aging, albedos of the streets change. Fig. 6 shows measurements of the albedos of chip sealed streets in San Jose as a function of their age at the times of measurement ("2000" means Oct. 2000 indicated by the diamonds and "2001" means May 2001 indicated by circles). The general trend is for the albedo to decrease with age, from its initial value of about 0.20 to an asymptote at 5 years of about 0.12 .

The weather in the San Jose area has the characteristic of being dry in summer; generally rain falls only between November to April. Thus, in May 2001 we returned to some of the streets that we had measured in October 2000 to measure whether the intervening rains had any cleaning effect on the pavements. The data indicated by circles in Fig. 6 are the albedos measured in May 2001 , and are of the same streets as measured when their age was about a year less. For example, the circle at 1 year of age is the same location as the diamond at 0 years of age. This case showed a particularly dramatic decrease in albedo. This was a practically newly paved street in 2000 with a high albedo of 0.20. By May of 2001 the albedo had been reduced to 0.11, like that of an old street. (The surface also showed cracks, unlike any other street we observed.) The explanation was easy to find: this street was next to the San Jose Medical Center. The amount of traffic is unusually high for a residential street. Moreover it is traversed by ambulances, that are heavier than ordinary autos and damage the street more rapidly. This illustrates the point that the kind of use the street undergoes has a profound effect on the choice of construction method, and the history of its albedo.

In another attempt to observe an effect of washing, we revisited a chip seal that was 3 years old in 2000. Its albedo then was about 0.14. By May 2001 its average albedo had decreased to about 0.11 . We then selected a particularly dark area $(\hat{\mathrm{a}}=0.10)$ and scrubbed it manually with a brush using a household (Amway) liquid detergent in water. We then hosed it down with water and let it dry. This resulted in a negligible increase in albedo. (These are the lower two circles at 4 years of age in Fig. 6.) The changes are within the uncertainty of the measurement, so the indication is that neither rain nor manual scrubbing removes much of the soiling of these chip seals. Of course, it may be that scrubbing by machine and the use of more suitable detergents might raise the albedo significantly.

Interestingly, in an earlier study of asphalt concrete pavements (Pomerantz et al. 2000), we reported that the albedo of $\mathrm{AC}$ pavements that were more than 5 years old also averaged 0.12 . We show that data in Fig. 7, where the East Bay AC data are seen to rise from an initial low value of 0.04 and overlap the San Jose chip seal albedos (measured in 2000) after about five years. 
To have a visual sense of the darkness of pavements of various albedos, we show in Fig. 8 a photograph of an intersection of a recently placed asphaltic pavement (across the center of the photo) and chip sealed streets (at the bottom and top). The chip seal is noticeably lighter, but not glaringly so.

\subsection{Temperatures of chip seal pavements}

The aspect of reflective surfaces that concerns us is the lower temperature we expect them to attain in sunlight. We therefore measured the surface temperatures concurrently with the albedo measurements in Oct. 2000. These were clear sunny days in San Jose, with a peak air temperature of about $27^{\circ} \mathrm{C}\left(80^{\circ} \mathrm{F}\right)$. The measured pavement surface temperatures are plotted vs. the albedos of the surfaces in Fig. 9. The data point at â $=0.06$ is thick asphalt concrete, freshly paved. The other data refer to the chip seals plotted in Fig. 6.

The least-square fit to the data has a slope of $-62^{\circ} \mathrm{C}\left(-111^{\circ} \mathrm{F}\right)$ (for a change in â from 0 to 1.). This is a change in pavement temperature by about $-6^{\circ} \mathrm{C}\left(-11^{\circ} \mathrm{F}\right)$ for a 0.1 change in albedo. Recall that in $\S 2.2$ we found a variation of $\mathrm{AC}$ pavement temperatures of about $-5^{\circ} \mathrm{C}\left(-9^{\circ} \mathrm{F}\right)$ (for a change in $\hat{a}=0.1$ ). Some caveats should be added about the chip seal result. It is perhaps unfair to include an AC pavement in a comparison to chip seals because its thermal properties may be somewhat unlike a chip seal. The heated surface of an AC pavement has an initial conduction path through asphalt. Although the asphalt is thin, it is a poorer thermal conductor than stone. There is also a methodological problem with all such measurements in that the pavement temperatures are varying with the time of day (see Figs. 4 and 5, for example). Thus if we measure the albedo and temperature at noon at one place, and compare to an albedo and temperature measured at a different time, at another place, the comparison is not exact. In principle, we should measure the albedos and temperatures at all locations at the same time. In practice we do not have the personnel and equipment to make such simultaneous measurements. The problem is mitigated somewhat because we make the measurements during the hours between about solar noon and 3 PM when the pavements are passing through their maximum temperatures (see Figs. 4 and 5), and are thus most slowly varying with time. Nevertheless, there may be some inaccuracy: the point at â $=0.09$ was taken about 10 mins before noon and the temperature seems low. The overall result, however, seems incontrovertible. The chip seals employing aggregate with $\hat{a}=0.2$ decrease the surface temperature by at least $15^{\circ} \mathrm{F}$ below that of a fresh AC pavement. After aging from 3 to 5 years, both the chip seal and the AC approach the same â and their temperatures tend to equal each other.

\section{Conclusions}

There is little doubt that hot cities would benefit if their pavements were as light-colored as possible. It is also desirable to enhance or replace AC with technologies that are familiar to public works departments, to minimize resistance to change. The physical properties of two candidates for cooler pavements, Portland cement concrete and chip seals, are examined in this report.

We find that PCC in place in the San Francisco Bay area has a wide range of albedos and hence temperatures. Their albedos vary from a low of about $\hat{a}=0.18$ to a maximum of about $\hat{a}=0.35$. We were unable to establish the ages or starting materials of the PCC pavements and thus cannot explain the albedos. We note that they are higher than that of aged asphalt-based pavements that we measured. 
For chip seals we were able to learn the ages and starting materials, because the City of San Jose has used chip seals as the standard maintenance technique for more than 20 years. They have good records and recollections. We found that a newly placed chip seal has about the same albedo as the aggregate used (in this case $\hat{a}=0.20$ ). As time passes, the chip seals' albedos tend to decrease to an asymptotic value of about $\hat{a}=0.12$ after about 5 years. Interestingly, this is the same value to which AC albedos rise, in about 3-5 years (Pomerantz et al. 2000). We noted that the rate of change of the albedo depends on the amount of use and the local conditions of the pavements. The rain in San Jose did not noticeably clean the pavements. Our attempts at manually scrubbing the chip seals were ineffectual, but more powerful methods might succeed.

We believe it is significant that the average of the PCC albedos is distinctly higher than that of aged AC and chip seals. This means that the final â of a pavement is not determined solely by the aging and soiling; it is influenced by the original pavement material. Thus, one can infer that all pavements will not finally become the color of the dirt; it does matter what the material is. In this regard it would be interesting to make chip seals with much higher albedos and observe the changes they undergo.

We find that the peak surface temperature varies with albedo by about $-5^{\circ} \mathrm{C}\left(-9^{\circ} \mathrm{F}\right)$ for a change in albedo of 0.1 for all the types of pavements that we have studied. This was determined experimentally for chip seals in the present work, and for $\mathrm{AC}$ in an earlier paper (Pomerantz et al. 2000). This agrees with the theoretical results on AC pavements (Solaimanian et al. 1993). For PCC this value was found from the simulations of the present work and also from an experiment. The similarity of the results for different pavements reflects the similarity of the thermal diffusivities and emissivities of the AC and PCC materials. This value of peak temperature vs. albedo is in approximate agreement with earlier results on a variety of materials (Rosenfeld et al. 1995), where a dependence of about $-5^{\circ} \mathrm{C}\left(-8^{\circ} \mathrm{F}\right)$ per increase of 0.1 in albedo is reported.

There are other factors that may affect the temperature of pavements. AC and PCC differ in their attraction to water. Asphalt, like all oils, repels water whereas PCC, like minerals, attracts water. Thus it is likely that a PCC pavement will capture more water, the dew, than will AC. The subsequent evaporation of the water will tend to cool the pavement, suggesting that PCC will remain cooler longer. Experiments with porous and ceramic blocks suggest that small pores do result in cooler surfaces (Asaeda et al. 2000). Further work on the different types and structures of paving materials is desirable.

\section{Acknowledgments}

This work was supported by the Environmental Protection Agency (EPA), under IAG No. DW899335101, and by the Assistant Secretary for Energy Efficiency and Renewable Energy, Building Technologies, of the U.S. Department of Energy (DOE) under contract No. DEAC0376SF00098. Through the auspices of David Akers, California Cement Promotion Council, we received samples of PCC and their constituents from Doug Taylor of Tilbury Materials, Seattle WA, John Halverson, Calaveras Materials Inc., Santa Ana, CA, Louis Valenzuela of Southdown, Brea, CA. Rachel Anderson made some measurements. Useful comments were made by Martha Van Geem of the Construction Technology Laboratories, Mike Ting, Drs. Paul Berdahl and John Harvey. The cooperation of Amanda Lei, of the San Jose Department of Streets and Traffic, facilitated the measurements of chip seals and learning their histories. 


\section{Appendix A: Process of making and applying PCC:}

The raw materials (Brunauer et al. 1964) of ordinary Portland cement are limestone (calcium carbonates, $\mathrm{CaCO}_{3}$ ) or oyster shells, and clay, which contains iron oxides, silica, and alumina. The steps in making cement are: 1) crushing and grinding of raw materials separately, 2) mixing raw materials in the proper proportions, 3) burning the mixture in a kiln to obtain "clinker," creating lime $(\mathrm{CaO})$. 4) grinding the clinker with $5 \%$ gypsum $\left(\mathrm{CaSO}_{4} \cdot 2 \mathrm{H}_{2} \mathrm{O}\right)$, to control the time of setting of the cement. The grinding can be done when the raw material has been wetted, or is dry, or the dry-ground materials may be wetted into nodules before being fed into the kiln. These are known as the "wet," "dry" and "semidry" processes.

When mixed with water, an exothermic chemical reaction, hydration of the cement, occurs. This can raise the concrete temperature above the ambient by as much as $40{ }^{\circ} \mathrm{C}$. The release of heat results from the formation of more stable compounds and indicates that the concrete is hardening and gaining strength.

Cement concrete is strong in compression, but fails more easily under tension or torsion. To improve the resistance to tension or torsion, steel reinforcing-bars ("rebar") may be embedded in PCC to produce reinforced concrete. To improve tensile strength, the rebar can be put in tension, thus applying compression to the PCC when the steel is released. This is prestresssed concrete. If tension does occur, it must first overcome the compressive condition, which is set to exceed the likely tension.

Cement concrete pavings can be applied over a crushed rock subsurface, and thus be the sole continuous surface. The thickness that is applied depends on the use. For jet airport runways it can be up to about 1 meter (39 inches) thick. For typical roads it is about 10 to $30 \mathrm{~cm}$. (4 to 12 inches) thick. PCC can also be used as a topping of an asphalt surface that is already in place. The technique is roughen the asphalt to a depth of about $5 \mathrm{~cm}$ (2 in.) and then apply from 5 to 10 $\mathrm{cm}$ (2 to 4 in.) of PCC. This is known as "whitetopping" to distinguish it from a similar process using asphalt concrete, commonly referred to as "blacktopping."

For more information, see websites of the Portland Cement Association:

http://www.portcement.org/.

For answers to frequently asked questions about PCC, see:

http://www.concretenetwork.com/concrete/faq.htm.

A list of PCC companies is at

http://www.global-cement.dk/files/north_america/north_america.htm.

\section{References}

AEMA (1995). Recommended Performance Guidelines, Asphalt Emulsion Manufacturers Association. Second Edition.

Akbari, H., S. Davis, S. Dorsano, J. Huang and S. Winnett, Eds. (1992). Cooling Our Communities: A Guidebook on Tree Planting and Light-Colored Surfacing, U.S. Environmental Protection Agency, Washington, D.C. 
Akbari, H., M. Pomerantz and H. Taha (2001). "Cool Surfaces and Shade Trees to Reduce Energy Use and Improve Air Quality in Urban Areas,” Solar Energy, 70 295-310.

Akbari, H., L. S. Rose and H. Taha (1999). Characterizing the Fabric of the Urban Environment: A Case Study of Sacramento, CA., Lawrence Berkeley National Laboratory. LBNL-44688.

Asaeda, T., V. T. Ca and A. Wake (1996). "Heat Storage of Pavement and its Effect on the Lower Atmosphere," Atmospheric Environment, 30 413-427.

Asaeda, T. and T. C. Vu (2000). "Characteristics of permeable pavement during hot summer weather and impact on the thermal environment," J. Building Environment, 35 363-375.

Asphalt-Institute (1989). The Asphalt Handbook, The Asphalt Institute, Lexington KT.

Brunauer, S. and L. E. Copeland (1964). "The Chemistry of Concrete," Scientific American 210, (April 1964), $80-92$.

Cal-Stats (1990). California Statistical Abstract, Department of Finance, State of California. San Francisco county is taken as representative of a totally urbanized area.

Doll, D., J. K. S. Ching and J. Kaneshiro (1985). "Parametrization of subsurface heating for soil and concrete using net radiation data," Boundary-Layer Meteorol., 10 351-372.

FHWA (1984). Construction and Rehabilitation of Concrete Pavement-Instructor's Guide, Federal Highway Administration. HHI-22/11-84(400)EWR.

FHWA (1997). "Preventive Maintenance Yields Huge Savings, Says Michigan Study," Focus, Sept. 19973.

Jakob, M. and G. A. Hawkins (1957). Elememts of Heat Transfer, 3 rd Ed., New York, NY, John Wiley and Sons.

Janisch, D. W. (1992). Seal Coat Procedures and Problems, Minnesota Local Road Research Board, MN DOT. Research Implementaion Series, Number 12.

Kittel, C. (1976). Introduction to Solid State Physics, 5 th Ed., New York, Wiley and Sons.

Leighou, R. B. (1942). Chemistry of Engineering Materials, 4 th Ed., New York, McGraw-HIll.

Levinson, R. and H. Akbari (2002). "Effects of composition and exposure on the solar reflectance of portland cement concrete," Cement and Concrete Research, 32 1679-1698. Also. Lawrence Berkeley National Laboratory report \#LBNL-48334.

Mantell, C. L., Ed. (1958). Engineering Materials Handbook, McGraw-Hill, New York.

Means, R. S. (1996). Building Construction Cost Data, 9 th Ed., Kingston, MA, R. S. Means Company, Inc.

Morse, P. M. and H. Feshbach (1953). Methods of Theoretical Physics New York, McGrawHill.

Pomerantz, M., B. Pon, H. Akbari and S.-C. Chang (2000). The Effect of Pavements' Temperatures on Air Temperatures in Large Cities, Lawrence Berkeley National Laboratory. LBNL-43442.

Rosenfeld, A. H., H. Akbari, S. Bretz, B. L. Fishman, D. M. Kurn, D. J. Sailor and H. G. Taha (1995). "Mitigation of Urban Heat Islands: Materials, Utility Programs, Updates," Energy and Buildings, 22 255-265. 
Solaimanian, M. and T. W. Kennedy (1993). "Predicting Maximum Pavement Surface Temperature Using Maximum Air Temperature and Hourly Solar Radiation," Transportation Research Record, 1417 1-11.

Taha, H., S. Konopacki and S. Gabersek (1999). "Impacts of Large-Scale Surface Modifications on Meteorological Conditions and Energy Use: A 10-Region Modeling Study," Theor. Appl. Climatol., 62 175-185. Also, Report No. LBNL-39335.

Ting, M., J. Koomey and M. Pomerantz (2001). Preliminary Economic and Policy Evaluation of Reflective Pavements, Lawrence Berkeley National Laboratory. LBNL-45864. 


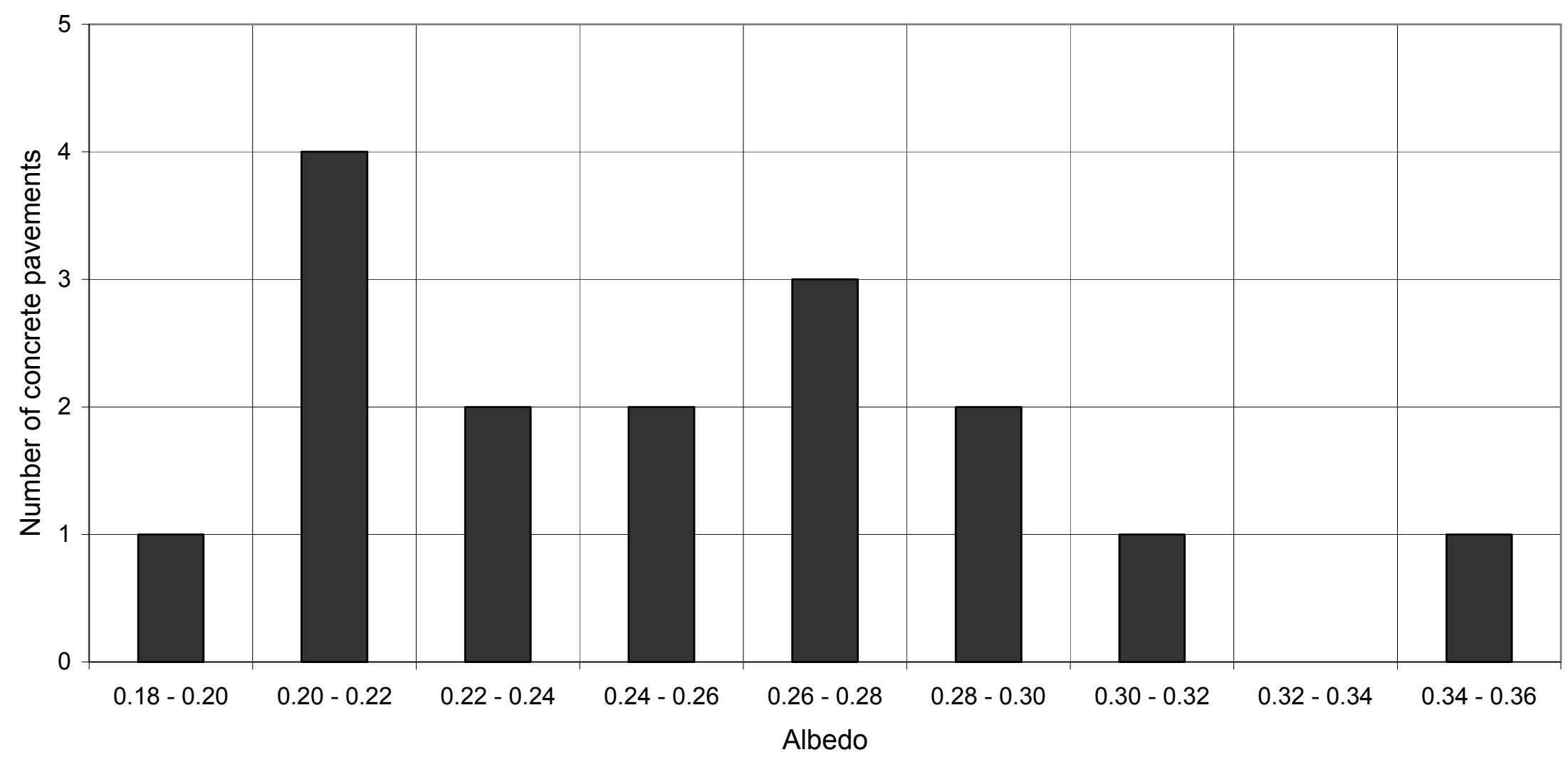

Fig. 1 Histogram of number of PCC pavements (of various ages) vs. their measured albedos. 


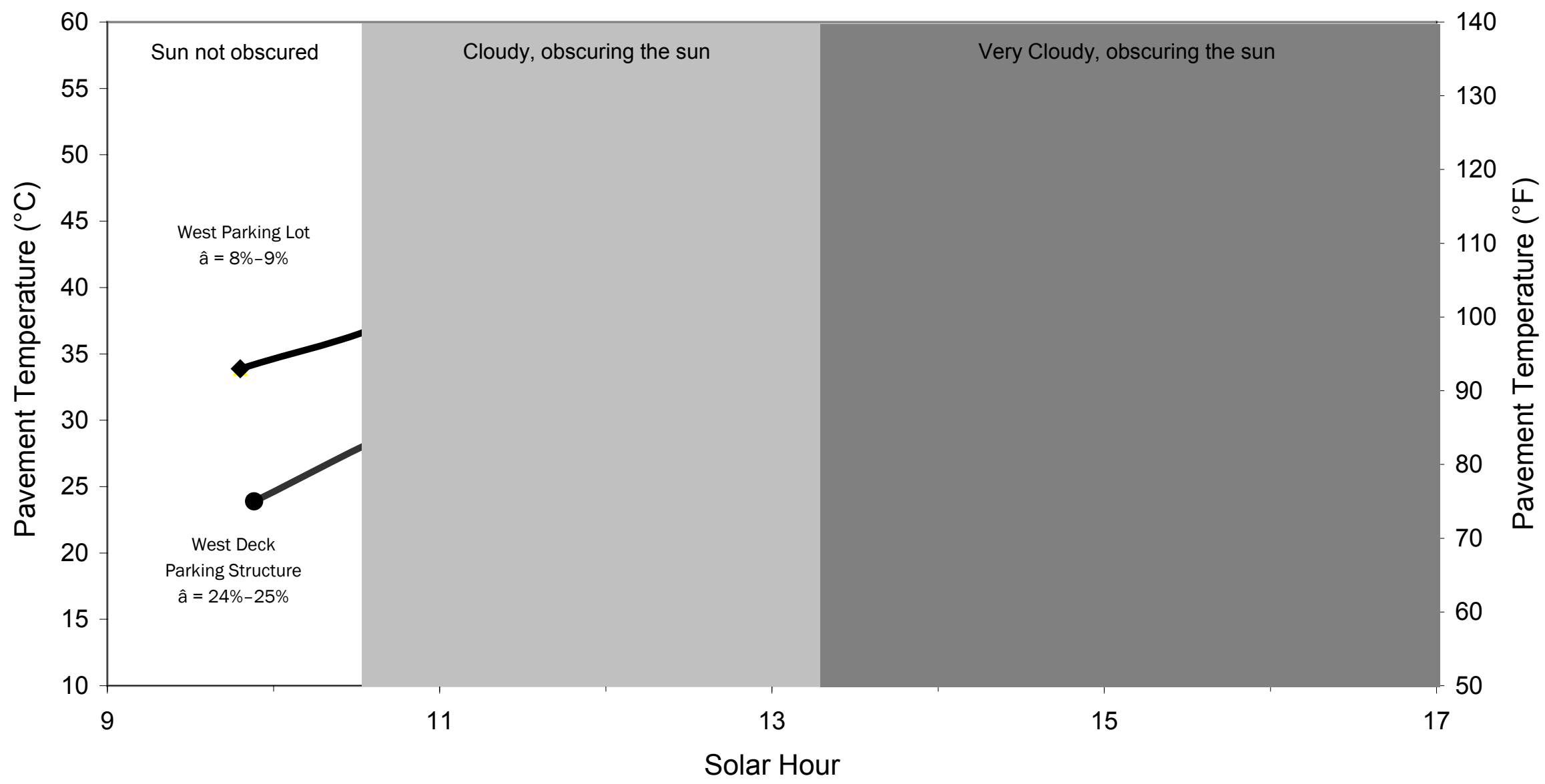

Fig. 2. Measured surface temperatures vs. solar time of a PCC pavement (higher albedo) and an AC pavement (lower albedo), Concord, CA, 14 Oct. 1999. 


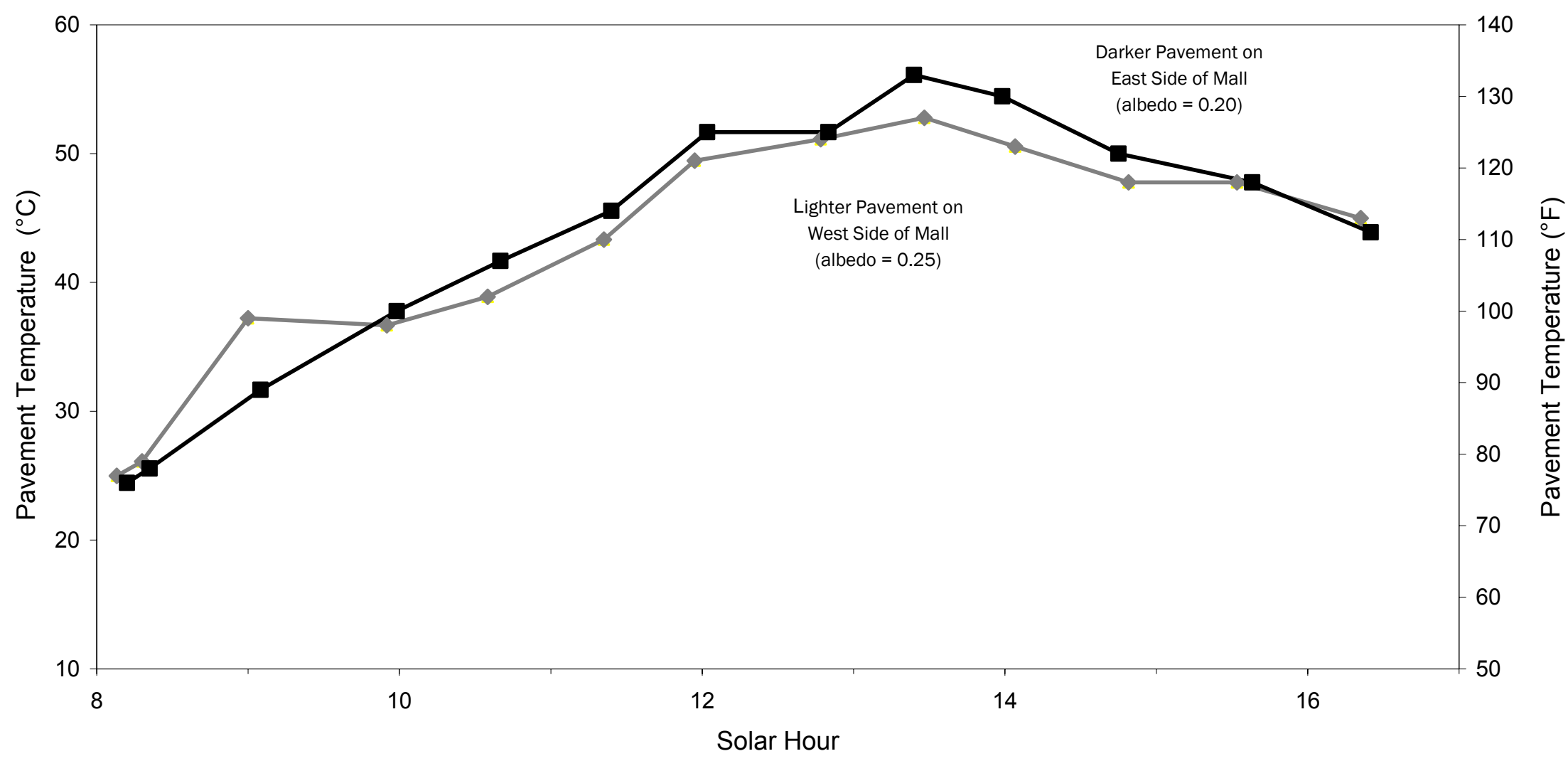

Fig. 3. Measured surface temperatures vs. solar time of two PCC pavements of different albedos, Concord, CA, 29 Sept. 1999. 


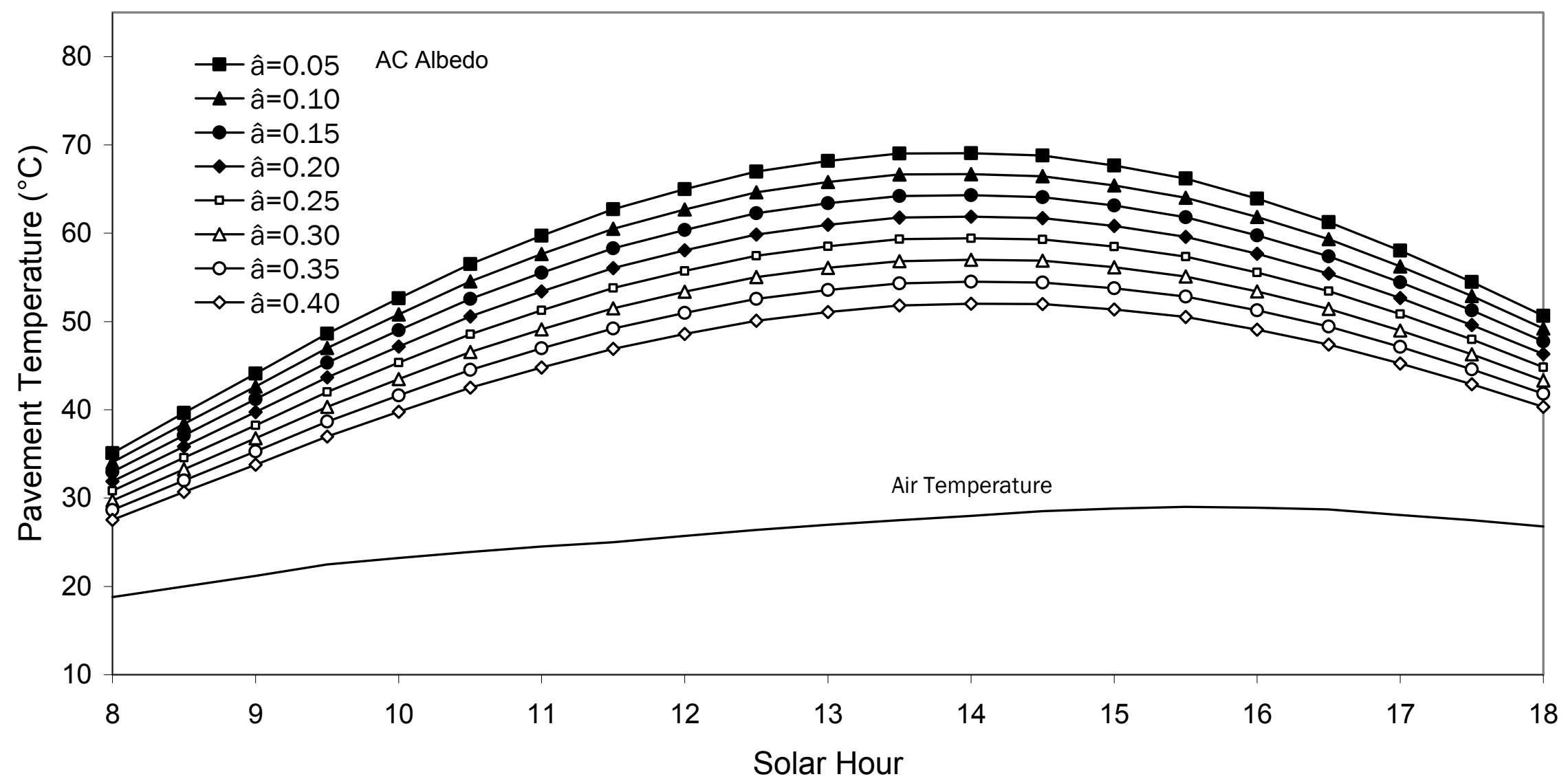

Fig. 4. Calculated surface temperatures vs. time of AC pavements of various albedos. The air temperatures used in the calculation are also shown. 


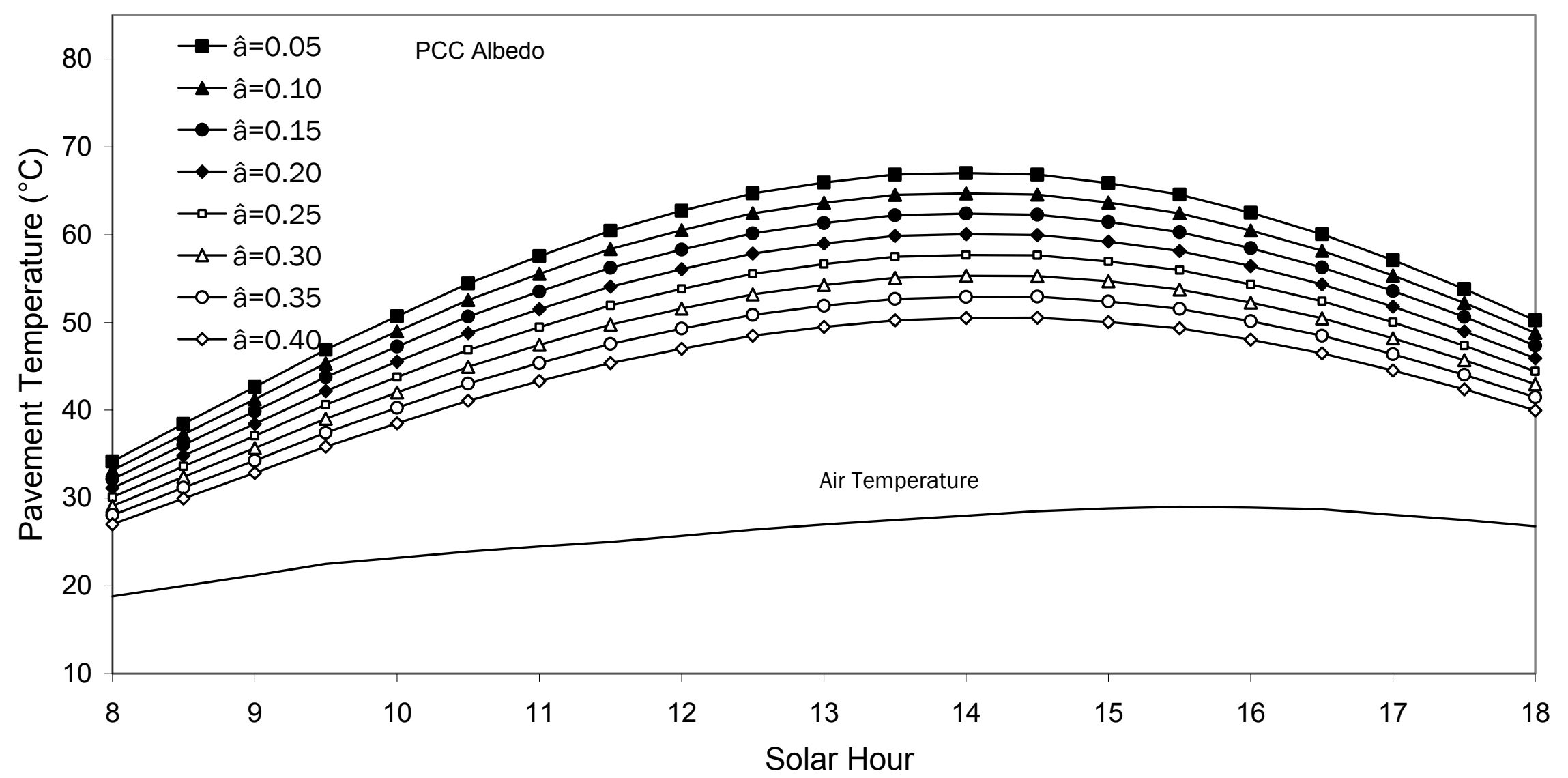

Fig. 5. Calculated surface temperatures vs. time of PCC pavements. The albedos and air temperatures are the same as in Fig. 4. 


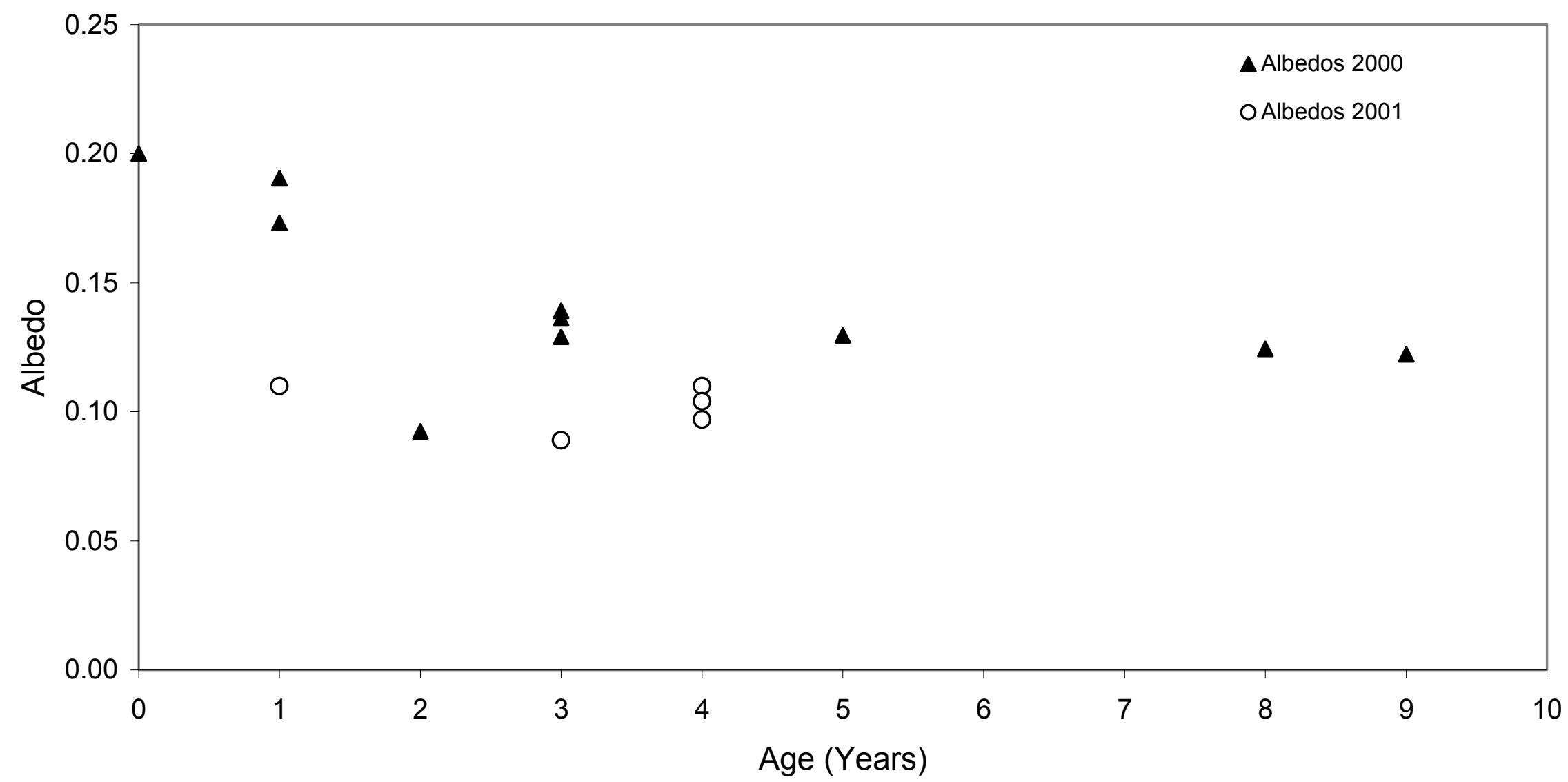

Fig. 6. Albedos vs. age of chip-sealed streets in San Jose, CA. Measurements were made in Sept. 2000 and May 2001. 


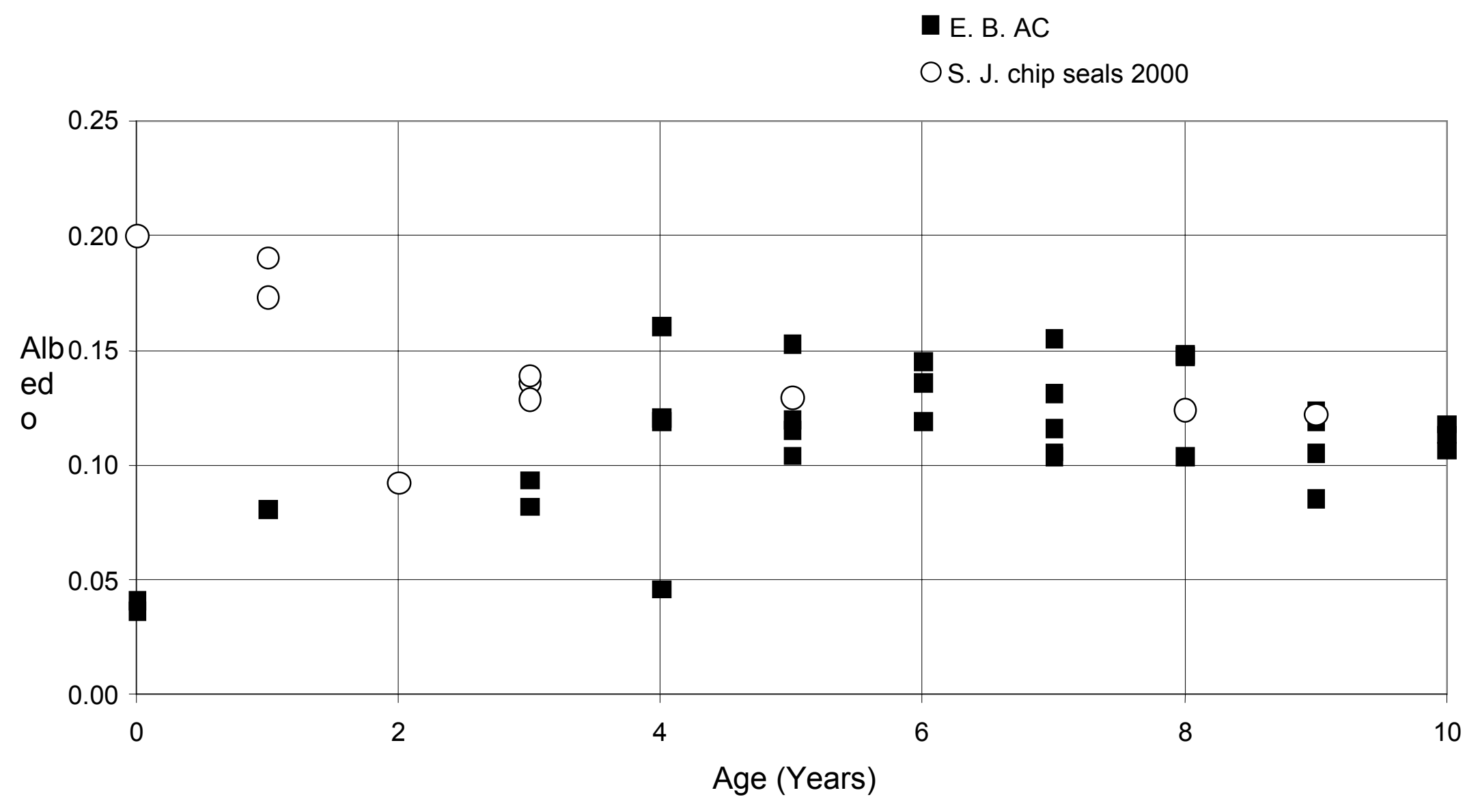

Fig. 7. Albedos of chip-sealed streets in San Jose, CA, and AC pavements in the East Bay region of San Francisco, vs. age 

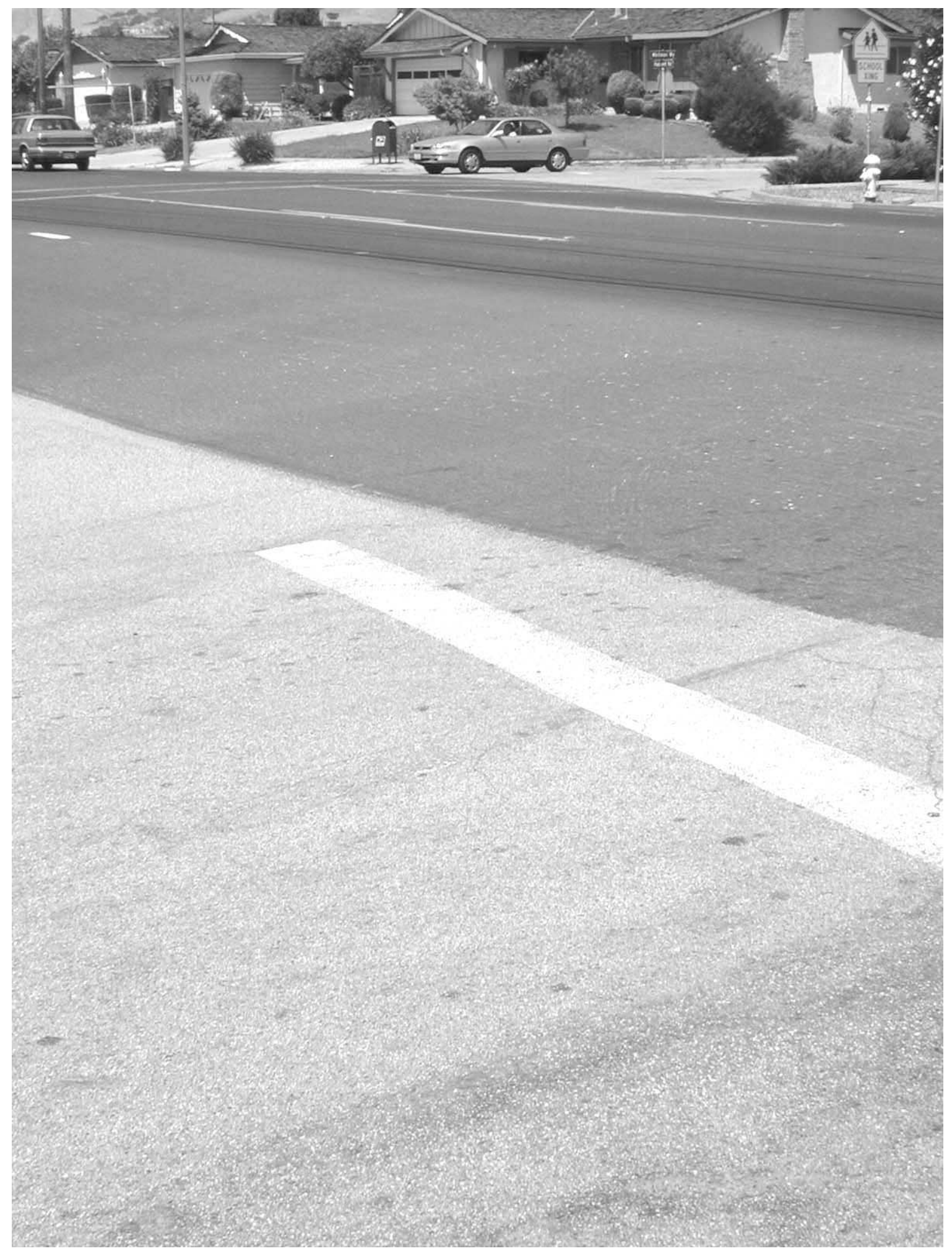

Fig. 8. Photograph of streets in San Jose, CA, that are paved with asphalt (in the middle) and chip seals (at bottom and top). 


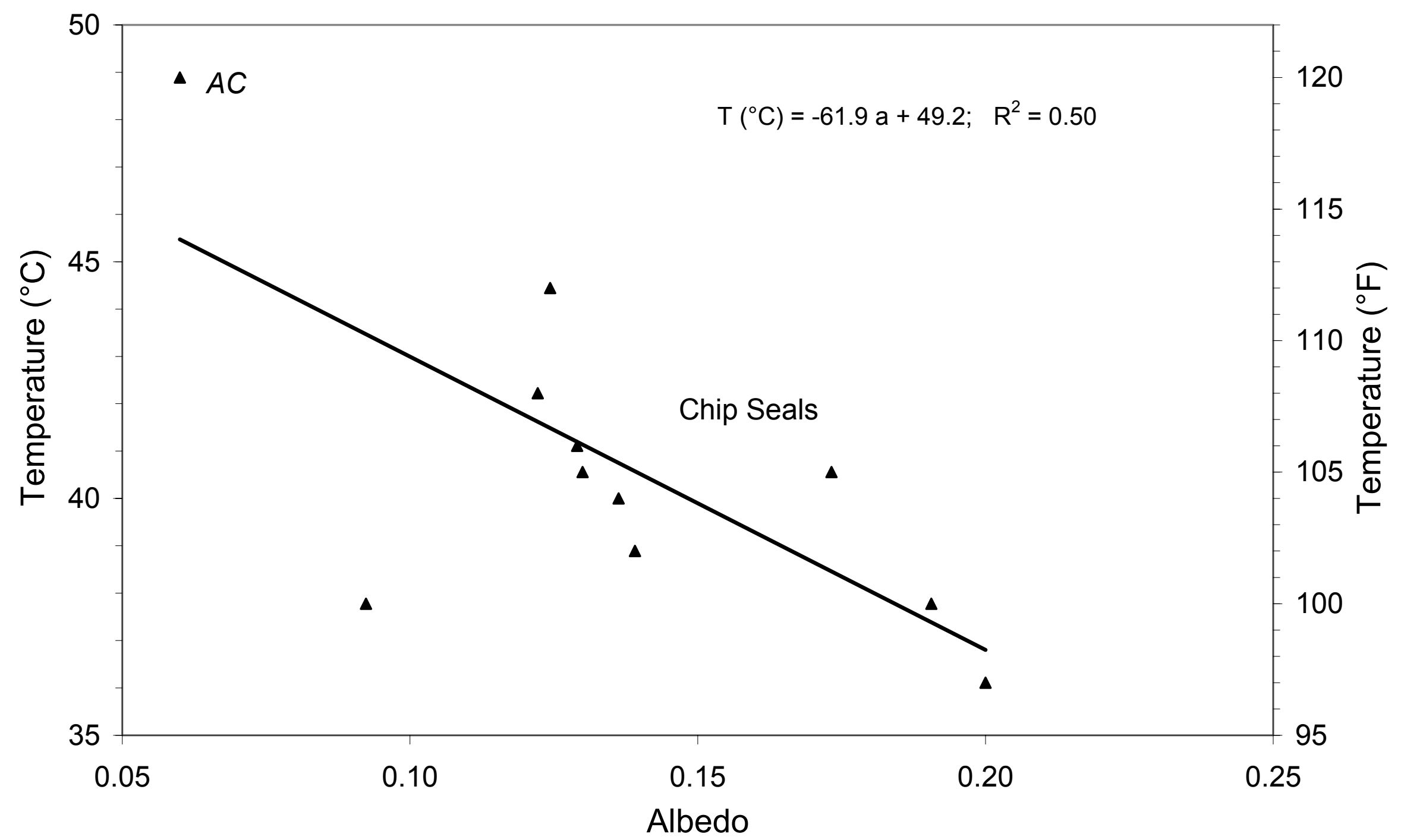

Fig. 9. Temperatures vs. albedos of chip seals (and an AC pavement) measured in the year 2000. 